\title{
Exercise Intensity Modulation of Hepatic Lipid Metabolism
}

\author{
Fábio S. Lira, ${ }^{1,2}$ Luiz C. Carnevali Jr, ${ }^{2}$ Nelo E. Zanchi, ${ }^{3}$ Ronaldo VT. Santos, ${ }^{4}$ \\ Jean Marc Lavoie, ${ }^{5}$ and Marília Seelaender ${ }^{2}$ \\ ${ }^{1}$ Laboratory of Exercise Biochemistry and Physiology, Health Sciences Unit, University of Southern Santa Catarina, \\ 88806-000 Criciúma, SC, Brazil \\ ${ }^{2}$ Cancer Metabolism Research Group, Institute of Biomedical Sciences, University of São Paulo, 05508-900 São Paulo, SP, Brazil \\ ${ }^{3}$ Institute of Biomedical Science, University of São Paulo, 05508-900 São Paulo, SP, Brazil \\ ${ }^{4}$ Departamento de Biociências, Universidade Federal de São Paulo, Campus Baixada Santista, Brazil \\ ${ }^{5}$ Department of Kinesiology, University of Montreal, Montreal, P.O. Box 6128, ON, Canada, H3C 3J7
}

Correspondence should be addressed to Fábio S. Lira, fabiolira@unesc.net and Marília Seelaender, seelaend@icb.usp.br

Received 14 August 2011; Accepted 11 January 2012

Academic Editor: Maria Luz Fernandez

Copyright (C 2012 Fábio S. Lira et al. This is an open access article distributed under the Creative Commons Attribution License, which permits unrestricted use, distribution, and reproduction in any medium, provided the original work is properly cited.

\begin{abstract}
Lipid metabolism in the liver is complex and involves the synthesis and secretion of very low density lipoproteins (VLDL), ketone bodies, and high rates of fatty acid oxidation, synthesis, and esterification. Exercise training induces several changes in lipid metabolism in the liver and affects VLDL secretion and fatty acid oxidation. These alterations are even more conspicuous in disease, as in obesity, and cancer cachexia. Our understanding of the mechanisms leading to metabolic adaptations in the liver as induced by exercise training has advanced considerably in the recent years, but much remains to be addressed. More recently, the adoption of high intensity exercise training has been put forward as a means of modulating hepatic metabolism. The purpose of the present paper is to summarise and discuss the merit of such new knowledge.
\end{abstract}

\section{Introduction}

Lipid metabolism involves numerous pathways that are, at least partly, interdependent. The lipid available for liver uptake may derive from the diet [1] or from mobilisation of fatty acids (FAs) from the adipose tissue, followed by the transport in the circulation, [2], which requires specific transporters such as albumin, while diet lipids in the form of triacylglycerol (TG) are transported by chylomicra and very low density lipoprotein (VLDL). In the liver, specific transporters (FAT and L-FABP) are involved in the uptake and intracellular traffic of these molecules $[3,4]$. The hepatocyte then carries out TG hydrolysis to diacylglycerol (performed by microsomal lipase) and then to fatty acids, which are then activated and combined with coenzyme A, allowing their transport into the reticulum luminal space by intraluminal carnitine acyltransferase, where they are again esterified by TG diacylglycerol acyltransferase 2 [5], and become a part of nascent hepatic VLDL, or are stored within lipid droplets. Long-chain fatty acids (LCFA) deriving from exogenous sources or from intracellular pools may conversely be totally or partially oxidised by the hepatocyte mitochondria, a process that requires the action of an enzyme system, the carnitine palmitoyltransferases, and the channelling of the fatty acyl to either ketone body production or to B-oxidation. Finally, other possible fates of LCFA include the modification of the molecule, yielding, for instance, cholesterol and the incorporation into components of the cells, as into the membrane phospholipids [6]. The final fate of LCFA in the liver depends on a plethora of factors, including the quantity and type of fatty acid, hormonal regulation, contribution of innervation, and cell communication within the organ, to name a few.

Indeed, lipid metabolism in the liver is very complex, an aspect which is illustrated by the synthesis of VLDL. Most of the triacylglycerol (TG) recruited for the assembly of VLDL in the secretory apparatus of the hepatocyte is mobilised by lipolysis of preexistent cytosolic TG pools, followed by reesterification [7]. The assembly of VLDL in hepatocytes requires the microsomal triacylglycerol transfer protein (MTP), which transfers lipids, particularly TG, between membranes, 
and it is known to transfer TG to nascent apolipoprotein B (apoB) in vivo [3]. Some of the TG, however, is returned to the cytosolic pool in a process that is stimulated by insulin and inhibited by MTP [6]. As mentioned, every step of the VLDL synthesis is modulated by the physiological status of the organ.

It is well established that physical inactivity is related with excess plasma triglyceride (TG) concentration, which contributes, at least partially, to increased disease risk, as appearing in association with atherosclerosis, fatty liver, diabetes, and obesity $[8,9]$. On the other hand, chronic exercise training has been shown to present favorable effects on plasma lipid profile [10-12]. In this context, chronic exercise, especially moderate aerobic exercise $\left(50 \%-75 \% \mathrm{VO}_{2 \text { peak }}\right)$ has been considered one of the best nonpharmacological strategies for preventing and treating cardiovascular diseases, Position Stand American College of Sports Medicine 2011 [13].

Recently, high intensity exercise $\left(>80 \% \mathrm{VO}_{2 \text { peak }}\right)$ has been shown to markedly affect plasma lipid metabolism $[14,15]$. In addition, the higher energy expenditure achieved by associating volume and intensity seems to promote more prominent changes in liver lipoprotein and oxidative metabolism $[14,16]$. Considering the relevance of the liver for lipid metabolism regulation, the purpose of this paper is to summarise the specific effects of moderate and high intensity exercise on hepatic lipid metabolism.

\section{Exercise Intensity and Plasma Lipid Profile}

Several studies concerning the effects of exercise on plasma lipid profile have suggested that there is an intensity threshold for eliciting changes in these parameters (see Table 1). However, is there in fact a direct relationship between exercise intensity and lipid profile?

Significant improvements in HDL-cholesterol levels were reported in volunteers who exercised at $75 \%$ of maximal heart rate for 12 weeks, but no changes were observed in those who exercised at $65 \%$ of maximal heart rate [17]. In addition, Ferguson et al. [18] reported that after an aerobic exercise session, only the subjects with higher energy expenditure showed a reduction in TG and an increase in HDL-c concentrations, leading forth to the hypothesis of the existence of a threshold of energy expenditure associated with changes in lipoprotein profile. These data indicate that moderate intensity acute exercise that induces energy expenditure over 1,100-1,500 kcal, performed at approximately $70 \%$ of maximal oxygen consumption, has a greater effect on HDL cholesterol when compared with acute exercise with low energy expenditure. Therefore, intensity seems to be an important modulator of lipid profile [18].

Aellen et al. [2] reported that after 9 weeks of aerobic or anaerobic training, only aerobic exercise performed below lactate threshold was capable of inducing beneficial effects upon lipoprotein profile, while the anaerobic protocol (isocaloric expenditure energy) failed, especially in regard to the antiatherogenic lipoproteins. However, in a recent study, Tsekouras et al. [19] examined the effect of high intensity intervals of aerobic training (2 months of supervised highintensity interval training, 3 sessions/wk; running at 60 and
$90 \%$ of peak oxygen consumption in 4 min intervals for a total of $32 \mathrm{~min}$ ) on VLDL-TG secretion in men. They reported that subjects who had ran on the treadmill for 8 weeks at $90 \% \mathrm{VO}_{2 \text { peak }}$ presented a reduced rate of VLDL-TG secretion, suggesting that even high intensity exercise may induce changes in lipid profile. Thus, not only exercise intensity, but the effect of exercise intensity plus energy expenditure appear to modulate the rate of VLDL-TG secretion, which should be taken into consideration when designing or studying the exercise training effects focusing on promoting benefits upon lipoprotein profile.

\section{Effect of Diet Manipulation and Exercise on Lipid Profile}

It has been long recognised that diet manipulation in combination with exercise training is capable of modulating lipid profile. However, an important question to be considered is what is the effect of diet manipulation during different exercise intensities? In order to answer the first question, Maraki et al. [20] showed that even a low intensity aerobic exercise session $\left(30 \% \mathrm{VO}_{2 \text { peak }}\right)$, that theoretically does not induce a hypotriacylglycerolaemic effect $(<2 \mathrm{MJ})$, when combined with caloric restriction is capable of promoting one such response. On the other hand, we recently tested the effects of ingesting different $\mathrm{CHO}$ content diets and high intensity exercise on lipid profile [14]. Our aim was to compare the effects of high intensity exercise $\left(\sim 90 \% \mathrm{VO}_{2 \max }\right)$ and a dietary intervention (control, low, and high carbohydrate content) on blood lipid profile (VLDL, HDL cholesterol, LDL cholesterol, and total cholesterol). We hypothesised that high intensity exercise combined with carbohydrate supplementation could exert beneficial effects upon lipoprotein profile in healthy men. Although several studies showed that the reduction in TG and the increase in HDL-c concentrations promoted by exercise are dependent on a high energy expenditure, our results demonstrated that acute high intensity exercise, with low energy expenditure (in the absence of dietary interventions e.g., control group) was able to reduce LDL-c and total cholesterol levels. Having found out that acute high intensity exercise $\left(\sim 90 \% \mathrm{VO}_{2 \max }\right)$ reduces lipoprotein levels, even when associated with low energy expenditure, our group sought to investigate the effects of acute supramaximal intensity exercise (approximately 115\% $\mathrm{VO}_{2 \max }$ ) on lipoprotein metabolism [21]. In this study, the acute exercise session generated 50\% less energy expenditure than the previous study [14]. The data showed that a supramaximal exercise session has no significant effects on lipid metabolism [21]. Therefore, we suggest the existence of an "energy expenditure threshold" to induce changes in blood lipid levels.

Collectively, these data reinforce the hypothesis that there is a balance between intensity and the level of energy expenditure (that can be improved, especially during low intensity exercise, when reinforced by diet manipulation) that is able to induce changes in the lipoprotein profile, with special regard to VLDL secretion. 
TABle 1: Effects of Exercise Intensity on Hepatic Lipid Metabolism in Animal Models and Human.

\begin{tabular}{|c|c|c|c|c|}
\hline Reference & Sample & Intensity & Duration & Results \\
\hline Mondon et al. [22] & Rat males & $\begin{array}{l}\text { Moderate intensity } \\
60 \% \mathrm{VO}_{2 \max }\end{array}$ & 12 weeks & $\begin{array}{l}\text { Reduction TG, FFA levels, VLDL-TG secretion } \\
\text { was } 50 \% \text { lower in exercise trained rats }\end{array}$ \\
\hline Stein et al. [17] & Untrained men & $\begin{array}{l}65 \%, 75 \% \text { and } 85 \% \\
\text { maximal heart rate }\end{array}$ & 12 weeks & $\begin{array}{l}\text { Increases in the HDL cholesterol fractions in the } \\
75 \% \text { and } 85 \% \text { groups. Significant decreases in } \\
\text { LDL fractions in the } 75 \% \text { group }\end{array}$ \\
\hline Wallace et al. [23] & Trained men & $\begin{array}{l}\text { Moderate }(73 \% \text { of } \\
1 \mathrm{RM}) \text { and High } \\
\text { intensity }(92 \% 1 \mathrm{RM})\end{array}$ & Acute $90 \mathrm{~min}$ & $\begin{array}{l}\text { Increases HDL-c and its subfractions (HDL2 and } \\
\text { HDL3) in moderate when compared to high } \\
\text { intensity strength exercise }\end{array}$ \\
\hline Aellen et al. [2] & Untrained men & $\begin{array}{l}16 \text { trained intensity } \\
\text { above and } 17 \text { below the } \\
\text { anaerobic threshold }\end{array}$ & 9 weeks & $\begin{array}{l}\text { Increases in the HDL and HDL2 cholesterol } \\
\text { fractions in the below the anaerobic threshold }\end{array}$ \\
\hline Lira et al. [11] & Rat males & $\begin{array}{l}\text { Moderate intensity } \\
60 \% \mathrm{VO}_{2 \max }\end{array}$ & 8 weeks & $\begin{array}{l}\text { Exercised rats showed reduction of TG, VLDL-TG } \\
\text { levels, hepatic tissue TAG content, and lower rate } \\
\text { of hepatic VLDL secretion, gene expression of } \\
\text { apoB and MTP when compared with control rats }\end{array}$ \\
\hline Magkos et al. [15] & Untrained men & $\begin{array}{l}80 \% \text { of peak torque } \\
\text { production }\end{array}$ & Acute $90 \mathrm{~min}$ & $\begin{array}{l}\text { Resistance exercise lowered fasting plasma } \\
\text { VLDL-TG, increased VLDL-TG plasma clearance } \\
\text { rate, and shortened the mean residence time of } \\
\text { VLDL-TG in the circulation }\end{array}$ \\
\hline Tsekouras et al. [19] & Untrained men & 60 and $90 \%$ of $\mathrm{VO}_{2 \text { peak }}$ & 8 weeks & $\begin{array}{l}\text { High-intensity interval training VLDL-TG } \\
\text { concentration was reduced, and this was due to } \\
\text { reduced hepatic VLDL-TG secretion rate }\end{array}$ \\
\hline Tsekouras et al. [24] & Untrained men & $\begin{array}{l}80 \% \text { of peak torque } \\
\text { production }\end{array}$ & Acute $90 \mathrm{~min}$ & $\begin{array}{l}\text { Reduced VLDL-TAG concentrations, plasma } \\
\text { clearance rate of VLDL-TAG was significantly } \\
\text { higher after exercise than rest, and the mean } \\
\text { residence time of VLDL-TG in the circulation was } \\
\text { significantly shorter. Fasting plasma NEFA and } \\
\text { serum beta-hydroxybutyrate concentrations were } \\
\text { both significantly higher after exercise than rest }\end{array}$ \\
\hline Chapados et al. [12] & Rat males & $\begin{array}{l}\text { Moderate intensity } \\
60 \% \mathrm{VO}_{2 \max }\end{array}$ & 8 weeks & $\begin{array}{l}\text { Reduction in liver TG content, reduces VLDL } \\
\text { synthesis and/or secretion in fed rats probably via } \\
\text { MTP regulation }\end{array}$ \\
\hline Lira et al. [14] & Trained men & $90 \% \mathrm{VO}_{2 \max }$ & Acute $\sim 8 \mathrm{~min}$ & $\begin{array}{l}\text { Total cholesterol and LDL cholesterol were } \\
\text { reduced after the exhaustion and } 1 \mathrm{~h} \text { recovery } \\
\text { periods when compared with rest periods }\end{array}$ \\
\hline Lira et al. [25] & Untrained men & $\begin{array}{l}50 \%, 75 \%, 90 \% \text { and } \\
110 \%-1 \mathrm{RM}\end{array}$ & Acute $\sim 10 \mathrm{~min}$ & $\begin{array}{l}\text { The } 75 \%-1 \text { RM group demonstrated TG } \\
\text { reduction when compared to other groups. } \\
\text { HDL-c concentration was significantly greater } \\
\text { after resistance exercise in } 50 \%-1 \text { RM and } 75 \%-1 \\
\text { RM when compared to } 110 \%-1 \text { RM group }\end{array}$ \\
\hline Lira et al. [21] & Trained men & $115 \% \mathrm{VO}_{2 \max }$ & Acute $\sim 4 \mathrm{~min}$ & $\begin{array}{l}\text { There were no significant changes in the lipid } \\
\text { profile }\end{array}$ \\
\hline
\end{tabular}

$\mathrm{VO}_{2 \max }$ : maximal oxygen consumption. 1 RM: one repetition maximal. TG: triglycerides. FFA: free fatty acid. VLDL-TG: very low density lipoprotein. NEFA: non-esterified fatty acids. LDL: low density lipoprotein. HDL: high density lipoprotein. MTP: microsomal transfer protein. apoB: apolipoprotein B.

\section{Resistance Exercise and Lipid Metabolism}

Resistance exercise (mainly acute) has also been reported to affect lipid metabolism. Wallace et al. [23] showed that moderate acute resistance exercise (73\% of $1 \mathrm{RM}$ ) induced favorable modifications of lipid profile, increasing HDL-c and its subfractions (HDL2 and HDL3), when compared with high intensity resistance exercise (92\% $1 \mathrm{RM})$. This result can be a consequence to the differences between volume loading (high intensity exercise with low volume loading $-7.04=$ sets $\times$ repetitions $\times$ weight, and moderate intensity high volume loading $-31.13=$ sets $\times$ repetitions $\times$ weight). Thus, total energy expenditure may, at least partly, determine lipid metabolism modification following physical activity. As a potential alternative explanation, Tsekouras et al. [24] demonstrated that acute resistance exercise does not affect the rate of hepatic secretion of VLDL-TG, but increases VLDLTG plasma clearance rate by $26 \%$ as compared with the rest. Yet, the mean residence time of VLDL-TG in the circulation was significantly shorter after exercise than during rest (113 min after exercise than $144 \mathrm{~min}$ in rest). In fact, earlier, Magkos et al. [26] observed that acute resistance exercise was more efficient than aerobic exercise in increasing the clearance of VLDL and TG, and in decreasing the mean residence 
time of these lipoproteins in the circulation, suggesting a particular regulatory mechanism elicited by acute resistance exercise. Nonetheless, it remains unknown if such modification constitutes a fingerprint modification elicited in an intensity specific manner on lipid profile.

Magkos et al. [15] recently described possible routes of VLDL and TG removal from plasma, including hydrolysis by lipoprotein lipase (LPL) and possibly also by hepatic lipase, transfer of TG to other lipoproteins (e.g., HDL) via neutral lipid exchange, conversion of VLDL to lipoproteins of higher density, for example, intermediate-and low-density lipoproteins (IDL and LDL, resp.), as well as removal of the whole VLDL particle from plasma via interaction with hepatic and/ or peripheral receptors $[19,26,27]$. On the other hand, it is well documented that regular physical exercise is able to induce an augmentation of LPL gene expression and activity in the skeletal muscle $[27,28]$, resulting in decreased plasma TG content, which is also linked with decreased liver VLDL output $[11,12,22]$. These observations suggest a relationship between the increased catabolic rate of VLDL and TG during the early phase of recovery and repletion of the intramuscular TG pool. This is further supported by the transient increase in the transcription rate of muscle LPL described by Pilegaard et al. [29] $1 \mathrm{~h}$ after a 60-90 min of exhaustive knee-extensor exercise. Thus, whereas VLDL and TG turnover rate returned to its basal value 2-3 h after exercise, the peak in muscle LPL mass is reached $8 \mathrm{~h}$ after exercise [30]. This may constitute a critical regulatory mechanism elicited by exercise to reduce VLDL and TG levels.

In a recent study [25], we reported evidence that corroborates the hypothesis that acute resistance exercise in a moderate/high intensity (as well as aerobic exercise) may have antiatherogenics effects, particularly throughout lipid profile modulation. The experimental design consisted of five groups that performed acute exercise at different percentages of the one repetition maximum (1 RM); 50\%-1 RM, 75\%1 RM, 90\%-1 RM, and 110\%-1 RM group. The total volume (sets $\times$ reps $\times$ load) of the exercise was equalised. We demonstrated that acute resistance exercise may induce changes in lipid profile in a intensity-specific manner, taking into consideration that in such study although the intensity seems to be an important factor, the "threshold" must to be respected to induce benefits on lipid profile (low to moderate at 50\% and 75\% $1 \mathrm{RM}$ intensities seems to be more proper to induce benefits on lipid profile than high-intensity at $90 \%$ and $110 \%$ 1 RM exercise). Thus, the fitness professional should consider intensities $\leq$ or $=75 \%$ of $1 \mathrm{RM}$ when prescribing resistance training programs aimed at improving lipid profile. Chronically applied, such response might possibly yield greater benefits in increasing HDL-c and diminishing VLDL and TG lipoproteins, when compared with other strength training intensities. However, future studies are necessary to unveil potential mechanisms.

\section{Exercise Intensity and Lipid Oxidation in the Liver}

It is well documented that there is an important lipid profile adaptation, especially in regard to VLDL secretion, promoted by both acute and chronic exercise [15, 19, 26]. Such adaptation is usually related to an increased fatty acid delivery and oxidation in skeletal muscle promoted by LPL and the carnitine palmitoyltransferase (CPT) system adaptation even under intermittent high-intensity training [31]. However few studies have been performed to analyse the adaptations imposed by such stimuli upon hepatic lipid oxidation.

Observational studies in human suggest that increased habitual activity is inversely associated with intrahepatic TG content [32] and endurance training in animals reduces liver fat accumulation $[33,34]$. However it is not clear whether physical exercise has a direct impact on the enzymatic and molecular processes regulating lipogenesis and/or lipid oxidation in liver. Yasari et al. [35], showed that 8 weeks of treadmill exercise training $\left(\sim 60-70 \% \mathrm{VO}_{2 \max }\right)$ were able to downregulate the gene expression of SCD-1 (stearoyl-Coa desaturase-1), a rate-limiting enzyme in the biosynthesis of saturated-derived monounsaturated fat that are the major constituents of VLDL-TG in 2-week high fed rats. It is well documented that SCD-1 inhibition reduces lipogenesis and enhances hepatic fatty acid oxidation [36].

In a recent study performed by our group [37], we observed that 8 weeks of treadmill moderate training $(\sim 60 \%$ $\mathrm{VO}_{2 \max }$ ) increased CPT (carnitine palmitoyltransferase) complex maximal activity in the liver and prevented hepatic steatosis in trained tumour-bearing rats, reinforcing the hypothesis that an environmental factor such as exercise is able to optimise hepatic lipid oxidation. In agreement with such finding, Rector et al. [34, 38] reported that attenuation of hepatic steatosis in response to voluntary exercise training is associated with both increased hepatic fatty acid oxidation and likely reduced fatty acid synthesis, as indicated by reductions in key protein intermediates.

Malonyl-CoA is the first committed intermediate in the lipogenic pathway and is also an inhibitor of carnitine palmitoyltransferase-1 (CPT-1) the enzyme that controls the transfer of cytosolic long-chain fatty acyl CoA (LCFA CoA) into mitochondria. Therefore, CPT-1 activity can be limiting for fatty acid oxidation and ketogenesis in liver [39]. The decline in liver malonyl-CoA has been postulated to be responsible for the increase in blood ketone production during and after exercise [5]. Acetyl-CoA carboxylase (ACC) is the enzyme responsible for malonyl-CoA synthesis and its activation is allosterically regulated by citrate and inhibited by palmitoyl-CoA [40] and by AMPK (5'-AMP-activated protein kinase) phosphorylation [41].

Due to an increase in plasma TG and VLDL-TG concentration, it is likely that palmitoyl-CoA would have been elevated in the hepatocytes, bearing in mind that it represents an allosteric inhibitor of ACC and hence of malonyl-CoA synthesis $[40,42]$.

\section{Exercise Intensity and Hormone Profile}

Several studies show a clear effectiveness imposed by training intervention upon hepatic lipid content and a significant adaptation of hepatic metabolism to regular physical activity [43]. This adaptation is subject to a refined control by 
endocrine parameters, specially the insulin/glucagon ratio, and the stress promoted by exercise is known to modulate plasma concentrations of these hormones, which could be involved in the modulation of pathways controlling in the transcriptional regulation of hepatic genes after acute exercise [44]. Glucagon and insulin balance is an important contributor to the increase of hepatic fat oxidation during exercise. In response to moderate-intensity exercise, the secretion of glucagon and insulin from the pancreas generally increases and decreases, respectively [45].

During acute physical activity, an important interaction between the liver, muscle, and adipose tissue occurs, as to provide and maintain adequate blood levels of glucose, free fatty acids (FFAs), and consequently, ATP levels for the contracting muscle [46]. In addition, it is well known that during exercise, insulin levels are decreased allowing the mobilisation of the supracited fuel substrates supporting skeletal muscle contraction [47]. However, more recently Rector et al. [38], studying the Otsuka Long-Evans Tokushima Fatty rat, a common model of obesity, hepatic steatosis, and type 2 diabetes, examined the transition from free wheel access to voluntary running for 16 weeks (in order to prevent the development of hepatic steatosis) to a sedentary condition. After the cessation of daily exercise (5-173 h), no changes occurred in body weight, fat pad mass, food intake, serum insulin, hepatic triglycerides, or in the exercise-suppressed hepatic stearoyl-CoA desaturase-1, but complete hepatic fatty acid oxidation and mitochondrial enzyme activities were reduced in the rats that remain sedentary by 173 hours. A new question that arises from this topic is how slowly would be the transition of an active state (hyperkinesia) to a sedentary state in humans? Is it possible to avoid these deleterious effects upon the liver after the cessation of physical activity?

In another study, a recent question put foward by Noland et al. [48] was "does having an elevated initial oxidative capacity, provided by a genetic model with inherent initial differences in aerobic capacity allow protection against the development of obesity and diabetes?" To investigate this, the authors studied rats with low (LCR) and high (HCR) capacity endurance running fed with a pattern chow diet or a high fat diet (HFD). The authors demonstrated that elevated basal skeletal muscle oxidative capacity and the ability to preserve liver oxidative capacity may protect HCR rats from HFD-induced obesity and insulin resistance. Thus, renewed questions regarding insulin and the liver are of interest.

On the other hand, the increase in glucagon enhances the oxidation of NEFAs by stimulating pathways for fat oxidation within the liver [49], and this increased hepatic fat oxidation promoted by exercise produces energy that fuels gluconeogenesis [50]. The liver may itself modulate glucagon action in relation to exercise, considering that, under glucagon infusion, liver glucose production at rest is higher in trained individuals than in sedentary subjects [51], and also that exercise is able to promote a higher liver sensitivity to glucagon that could be due, at least in part, to an increased glucagon receptor density in liver [52]. The magnitude of these parameters generally increases with greater exercise duration and intensity [49]; however the question resides over the influence of acute and chronic exercise of different intensities upon glucagon secretion and liver metabolism modulation.

Most investigations concerning hepatic regulation during exercise have been performed at moderate intensities, although at higher intensities such regulation may be quite different and interesting. Firstly, the main identifiable difference is that during high intensity exercise (approximately $100 \%$ of $\mathrm{VO}_{2 \max }$ ) catecholamines may increase by 10 - to $15-$ fold, while arterial glucagon may increase, remain the same, or even decrease [53]. Secondly, circulating glucose levels often increases at high-intensity training and this may prevent the fall or even lead to a increase in insulin levels [54], suppressing glucagon effects, but not affecting catecholamine's function considerably $[55,56]$. In fact, earlier studies performed by Galbo [54] and Marker et al. [57] showed that glucagon response to high-intensity exercise was attenuated and led to impairment of liver glycogen breakdown. Furthermore, although catecholamines secretion is higher during high-intensity exercise $\left(74 \% \mathrm{VO}_{2 \max }\right)$ in comparison with moderate-intensity exercise $\left(41 \% \mathrm{VO}_{2 \max }\right)$, several earlier studies performed in humans showed that the attenuation of sympathetic nerve activity [58], along with experiments with liver transplant patients [59] does not affect the glucose response during a high-intensity exercise. Therefore, exercise performed at high-intensity or for a long duration may be modulating different responses.

The existence of energetic stress in liver during exercise is evidenced by the modulation of important metabolic pathways in this organ [60]. Exercise under moderate-/highintensity leads to exhaustion acknowledged to increase glucose production by the liver due to lower circulating glucose levels. Hence, cAMP concentration decreases and AMP-toATP ratio increases sufficiently to activate hepatic AMPactivated protein kinase (AMPK) [43, 61]. Berglund et al. [43] recently demonstrated that glucagon exerts a critical regulatory role in the liver, stimulating pathways linked to lipid metabolism in vivo and showed that activation of glucagon receptors is implicated in the pronounced transcriptional regulation of hepatic genes after running acute exhaustion exercise at $20 \mathrm{~m} / \mathrm{min}$ in rats. Glucagon action includes AMPK and p38 mitogen activated protein kinasedependent activation of peroxisome proliferator-activated receptor- $\alpha(\operatorname{PPAR} \alpha)$ [62]. This finding is important because PPAR $\alpha$ is a transcription factor critically required for many aspects of hepatic lipid metabolism [4].

Therefore, studies which showed a favourable lipid profile, including VLDL production by the liver, as induced by exercise, especially those performed until exhaustion or in a higher intensity [19] may be associated with adaptations modulated through glucagon stimulation, although a causal relationship needs still to be proven.

The energetic stress promoted by exercise also elevates plasma catecholamine concentrations, which, via the activation of hepatic adrenergic receptors, may also lead to MAPK activation [63]. However, it is not clear whether catecholamines are involved in the exercise-induced gene expression in the liver [44]. Nevertheless, several studies have been carried out $[58,64-66]$ to investigate the influence of adrenergic stimulation on glucose and lipid metabolism in the liver. 
Certainly, we cannot exclude the possibility that hepatic innervation is involved in the activation of hepatic MAPK signalling during exercise and also that the intensity of the stimulus may be an important factor in such modulation.

The information about decreasing liver glycogen content or glucose intermediates during exercise at different intensities is relayed through the afferent activity of hepatic innervation to the central nervous system, contributing to the modulation of the hormonal and consequently metabolic responses to exercise, controlling glucose levels and optimising lipid metabolism in liver.

\section{Conclusions}

In summary, the liver functions as a central manager of lipid metabolism in the organism, by regulating substrate availability to other tissues. The total energy expenditure generated during an exercise session is able to modulate the capacity of the liver to perform this task. However, more studies are necessary to elucidate which are the most important parameters inducing higher hepatic lipid secretion and oxidation during exercise, especially in regard to efforts of high intensity. The answers are very likely to contribute to more precise interventions in the population, contributing in a more consistent manner to health issues.

\section{Authors' Contribution}

F. S. Lira, L. C. canevali Jr, and N. E. Zanchi contributed equally to this work.

\section{References}

[1] J. H. Adams and J. H. Koeslag, "Post-exercise ketosis and the glycogen content of liver and muscle in rats on a high carbohydrate diet," European Journal of Applied Physiology and Occupational Physiology, vol. 59, no. 3, pp. 189-194, 1989.

[2] R. Aellen, W. Hollmann, and U. Boutellier, "Effects of aerobic and anaerobic training on plasma lipoproteins," International Journal of Sports Medicine, vol. 14, no. 7, pp. 396-400, 1993.

[3] S. O. Olofsson, P. Boström, L. Andersson, M. Rutberg, J. Perman, and J. Borén, "Lipid droplets as dynamic organelles connecting storage and efflux of lipids," Biochimica et Biophysica Acta, vol. 1791, no. 6, pp. 448-458, 2009.

[4] M. K. Badman, P. Pissios, A. R. Kennedy, G. Koukos, J. S. Flier, and E. Maratos-Flier, "Hepatic fibroblast growth factor 21 is regulated by PPAR $\alpha$ and is a key mediator of hepatic lipid metabolism in ketotic states," Cell Metabolism, vol. 5, no. 6, pp. 426-437, 2007.

[5] M. A. Beattie and W. W. Winder, "Attenuation of postexercise ketosis in fasted endurance-trained rats," The American Journal of Physiology, vol. 248, no. 1, pp. R63-R67, 1985.

[6] G. F. Gibbons, D. Wiggins, A. M. Brown, and A. M. Hebbachi, "Synthesis and function of hepatic very-low-density lipoprotein," Biochemical Society Transactions, vol. 32, no. 1, pp. 59 64, 2004.

[7] G. F. Gibbons, A. M. Brown, D. Wiggins, and R. Pease, "The roles of insulin and fatty acids in the regulation of hepatic very-low-density lipoprotein assembly," Journal of the Royal Society of Medicine, vol. 95, no. 42, pp. 23-32, 2002.
[8] F. S. Lira, J. C. Rosa, A. E. Lima-Silva et al., "Sedentary subjects have higher PAI-1 and lipoproteins levels than highly trained athletes," Diabetology and Metabolic Syndrome, vol. 2, no. 7, 2010.

[9] F. Magkos, J. M. Lavoie, K. Kantartzis, and A. Gastaldelli, "Diet and exercise in the treatment of Fatty liver," Journal of Nutrition and Metabolism, vol. 2012, Article ID 257671, 2 pages, 2012.

[10] M. A. Belmonte, M. S. Aoki, F. L. Tavares, and M. C. L. Seelaender, "Rat myocellular and perimysial intramuscular triacylglycerol: a histological approach," Medicine and Science in Sports and Exercise, vol. 36, no. 1, pp. 60-67, 2004.

[11] F. S. Lira, F. L. Tavares, A. S. Yamashita et al., "Effect of endurance training upon lipid metabolism in the liver of cachectic tumour-bearing rats," Cell Biochemistry and Function, vol. 26, no. 6, pp. 701-708, 2008.

[12] N. A. Chapados, M. Seelaender, E. Levy, and J. M. Lavoie, "Effects of exercise training on hepatic microsomal triglyceride transfer protein content in rats," Hormone and Metabolic Research, vol. 41, no. 4, pp. 287-293, 2009.

[13] C. E. Garber, B. Blissmer, M. R. Deschenes et al., "Quantity and quality of exercise for developing and maintaining cardiorespiratory, musculoskeletal, and neuromotor fitness in apparently healthy adults: guidance for prescribing exercise," Medicine and Science in Sports and Exercise, vol. 43, no. 7, pp. 1334-1359, 2011.

[14] F. S. Lira, N. E. Zanchi, A. E. Lima-Silva et al., "Acute highintensity exercise with low energy expenditure reduced LDLc and total cholesterol in men," European Journal of Applied Physiology, vol. 107, no. 2, pp. 203-210, 2009.

[15] F. Magkos, Y. E. Tsekouras, K. I. Prentzas et al., "Acute exerciseinduced changes in basal VLDL-triglyceride kinetics leading to hypotriglyceridemia manifest more readily after resistance than endurance exercise," Journal of Applied Physiology, vol. 105, no. 4, pp. 1228-1236, 2008.

[16] M. J. Gibala, "High-intensity interval training: a time-efficient strategy for health promotion?" Current Sports Medicine Reports, vol. 6, no. 4, pp. 211-213, 2007.

[17] R. A. Stein, D. W. Michielli, M. D. Glantz et al., "Effects of different exercise training intensities on lipoprotein cholesterol fractions in healthy middle-aged men," American Heart Journal, vol. 119, no. 2, pp. 277-283, 1990.

[18] M. A. Ferguson, N. L. Alderson, S. G. Trost, D. A. Essig, J. R. Burke, and J. L. Durstine, "Effects of four different single exercise sessions on lipids, lipoproteins, and lipoprotein lipase," Journal of Applied Physiology, vol. 85, no. 3, pp. 1169-1174, 1998.

[19] Y. E. Tsekouras, F. Magkos, Y. Kellas, K. N. Basioukas, S. A. Kavouras, and L. S. Sidossis, "High-intensity interval aerobic training reduces hepatic very low-density lipoprotein-triglyceride secretion rate in men," American Journal of Physiology-Endocrinology and Metabolism, vol. 295, no. 4, pp. E851E858, 2008.

[20] M. Maraki, N. Christodoulou, N. Aggelopoulou et al., "Exercise of low energy expenditure along with mild energy intake restriction acutely reduces fasting and postprandial triacylglycerolaemia in young women," British Journal of Nutrition, vol. 101, no. 3, pp. 408-416, 2009.

[21] F. S. Lira, N. E. Zanchi, A. E. Lima-Silva et al., "Is acute supramaximal exercise capable of modulating lipoprotein profile in healthy men?" European Journal of Clinical Investigation, vol. 40, no. 8, pp. 759-765, 2010.

[22] C. E. Mondon, C. B. Dolkas, T. Tobey, and G. M. Reaven, "Causes of triglyceride-lowering effect of exercise training in 
rats," Journal of Applied Physiology Respiratory Environmental and Exercise Physiology, vol. 57, no. 5, pp. 1466-1471, 1984.

[23] M. B. Wallace, R. J. Moffatt, E. M. Haymes, and N. R. Green, "Acute effects of resistance exercise on parameters of lipoprotein metabolism," Medicine and Science in Sports and Exercise, vol. 23, no. 2, pp. 199-204, 1991.

[24] Y. E. Tsekouras, F. Magkos, K. I. Prentzas et al., "A single bout of whole-body resistance exercise augments basal VLDL-triacylglycerol removal from plasma in healthy untrained men," Clinical Science, vol. 116, no. 2, pp. 147-156, 2009.

[25] F. S. Lira, A. S. Yamashita, M. C. Uchida et al., "Low and moderate, rather than high intensity strength exercise induces benefit regarding plasma lipid profile," Diabetology and Metabolic Syndrome, vol. 21, no. 2, p. 31, 2010.

[26] F. Magkos, Y. E. Tsekouras, K. I. Prentzas et al., "Acute exerciseinduced changes in basal VLDL-triglyceride kinetics leading to hypotriglyceridemia manifest more readily after resistance than endurance exercise," Journal of Applied Physiology, vol. 105, no. 4, pp. 1228-1236, 2008.

[27] F. Magkos, B. W. Patterson, B. S. Mohammed, and B. Mittendorfer, "A single 1-h bout of evening exercise increases basal FFA flux without affecting VLDL-triglyceride and VLDLapolipoprotein B-100 kinetics in untrained lean men," American Journal of Physiology-Endocrinology and Metabolism, vol. 292, no. 6, pp. E1568-E1574, 2007.

[28] R. L. Seip and C. F. Semenkovich, "Skeletal muscle lipoprotein lipase: molecular regulation and physiological effects in relation to exercise," Exercise and Sport Sciences Reviews, vol. 26, pp. 191-218, 1998.

[29] H. Pilegaard, G. A. Ordway, B. Saltin, and P. D. Neufer, "Transcriptional regulation of gene expression in human skeletal muscle during recovery from exercise," American Journal of Physiology-Endocrinology and Metabolism, vol. 279, no. 4, pp. E806-E814, 2000.

[30] R. L. Seip, K. Mair, T. G. Cole, and C. F. Semenkovich, "Induction of human skeletal muscle lipoprotein lipase gene expression by short-term exercise is transient," American Journal of Physiology-Endocrinology and Metabolism, vol. 272, no. 2, pp. E255-E261, 1997.

[31] R. M. Fisher, S. W. Coppack, S. M. Humphreys, G. F. Gibbons, and K. N. Frayn, "Human triacylglycerol-rich lipoprotein subfractions as substrates for lipoprotein lipase," Clinica Chimica Acta, vol. 236, no. 1, pp. 7-17, 1995.

[32] G. Perseghin, G. Lattuada, F. De Cobelli et al., "Habitual physical activity is associated with intrahepatic fat content in humans," Diabetes Care, vol. 30, no. 3, pp. 683-688, 2007.

[33] M. S. Gauthier, K. Couturier, J. G. Latour, and J. M. Lavoie, "Concurrent exercise prevents high-fat-diet-induced macrovesicular hepatic steatosis," Journal of Applied Physiology, vol. 94, no. 6, pp. 2127-2134, 2003.

[34] R. S. Rector, J. P. Thyfault, R. T. Morris et al., "Daily exercise increases hepatic fatty acid oxidation and prevents steatosis in Otsuka Long-Evans Tokushima Fatty rats," American Journal of Physiology, vol. 294, no. 3, pp. G619-G626, 2008.

[35] S. Yasari, D. Prud'Homme, D. Wang et al., "Exercise training decreases hepatic SCD-1 gene expression and protein content in rats," Molecular and Cellular Biochemistry, vol. 335, no. 1-2, pp. 291-299, 2010.

[36] G. Musso, R. Gambino, and M. Cassader, "Recent insights into hepatic lipid metabolism in non-alcoholic fatty liver disease (NAFLD)," Progress in Lipid Research, vol. 48, no. 1, pp. 1-26, 2009.

[37] F. S. Lira, A. S. Yamashita, J. R. L. Carnevalli et al., "Exercise training reduces PGE2 levels and restores steatosis hepatic in tumour-bearing rats," Hormone and Metabolic Research, vol. 42, no. 13, pp. 944-949, 2010.

[38] S. R. Rector, J. P. Thyfault, M. J. Laye et al., "Cessation of daily exercise dramatically alters precursors of hepatic steatosis in Otsuka Long-Evans Tokushima Fatty (OLETF) rats," Journal of Physiology, vol. 586, no. 17, pp. 4241-4249, 2008.

[39] J. D. McGarry and D. W. Foster, "Regulation of hepatic fatty acid oxidation and ketone body production," Annual Review of Biochemistry, vol. 49, pp. 395-420, 1980.

[40] D. G. Hardie, "Regulation of fatty acid synthesis via phosphorylation of acetyl-CoA carboxylase," Progress in Lipid Research, vol. 28, no. 2, pp. 117-146, 1989.

[41] N. B. Ruderman, H. Park, V. K. Kaushik et al., "AMPK as a metabolic switch in rat muscle, liver and adipose tissue after exercise," Acta Physiologica Scandinavica, vol. 178, no. 4, pp. 435-442, 2003.

[42] D. G. Hardie, J. Corton, Y. P. Ching, S. P. Davies, and S. Hawley, "Regulation of lipid metabolism by the AMP-activated protein kinase," Biochemical Society Transactions, vol. 25, no. 4, pp. 1229-1231, 1997.

[43] E. D. Berglund, L. Kang, R. S. Lee-Young et al., "Glucagon and lipid interactions in the regulation of hepatic AMPK signaling and expression of PPAR $\alpha$ and FGF21 transcripts in vivo," American Journal of Physiology-Endocrinology and Metabolism, vol. 299, no. 4, pp. E607-E614, 2010.

[44] M. Hoene and C. Weigert, "The stress response of the liver to physical exercise," Exercise Immunology Review, vol. 16, pp. 163-183, 2010.

[45] M. Hoene, R. Lehmann, A. M. Hennige et al., "Acute regulation of metabolic genes and insulin receptor substrates in the liver of mice by one single bout of treadmill exercise," Journal of Physiology, vol. 587, no. 1, pp. 241-252, 2009.

[46] P. Felig and J. Wahren, "Fuel homeostasis in exercise," New England Journal of Medicine, vol. 293, no. 21, pp. 1078-1084, 1975.

[47] H. Galbo, J. J. Holst, and N. J. Christensen, "The effect of different diets and of insulin on the hormonal response to prolonged exercise," Acta Physiologica Scandinavica, vol. 107, no. 1, pp. 19-32, 1979.

[48] R. C. Noland, J. P. Thyfault, S. T. Henes et al., "Artificial selection for high-capacity endurance running is protective against high-fat diet-induced insulin resistance," American Journal of Physiology-Endocrinology and Metabolism, vol. 293, no. 1, pp. E31-E41, 2007.

[49] D. H. Wasserman, R. M. O’Doherty, and B. A. Zinker, "Role of the endocrine pancreas in control of fuel metabolism by the liver during exercise," International Journal of Obesity, vol. 19, supplement 4, pp. S22-S30, 1995.

[50] D. H. Wasserman and A. D. Cherrington, "Hepatic fuel metabolism during muscular work: role and regulation," American Journal of Physiology-Endocrinology and Metabolism, vol. 260, no. 6, pp. E811-E824, 1991.

[51] R. Drouin, C. Lavoie, J. Bourque, F. Ducros, D. Poisson, and J. L. Chiasson, "Increased hepatic glucose production response to glucagon in trained subjects," American Journal of Physiology-Endocrinology and Metabolism, vol. 274, no. 1, pp. E23E28, 1998.

[52] A. Légaré, R. Drouin, M. Milot et al., "Increased density of glucagon receptors in liver from endurance-trained rats," American Journal of Physiology-Endocrinology and Metabolism, vol. 280, no. 1, pp. E193-E196, 2001.

[53] E. B. Marliss, E. Simantirakis, P. D. G. Miles et al., "Glucoregulatory and hormonal responses to repeated bouts of 
intense exercise in normal male subjects," Journal of Applied Physiology, vol. 71, no. 3, pp. 924-933, 1991.

[54] H. Galbo, "The hormonal response to exercise," Proceedings of the Nutrition Society, vol. 44, no. 2, pp. 257-266, 1985.

[55] D. C. Deibert and R. A. DeFronzo, "Epinephrine-induced insulin resistance in man," Journal of Clinical Investigation, vol. 65, no. 3, pp. 717-721, 1980.

[56] L. Saccà, N. Eigler, P. E. Cryer, and R. S. Sherwin, "Insulin antagonistic effects of epinephrine and glucagon in the dog," The American Journal of Physiology, vol. 237, no. 6, pp. E487492, 1979.

[57] J. C. Marker, D. A. Arnall, R. K. Conlee, and W. W. Winder, "Effect of adrenodemedullation on metabolic responses to high-intensity exercise," The American Journal of Physiology, vol. 251, no. 3, pp. R552-R559, 1986.

[58] M. Kjaer, K. Engfred, A. Fernandes, N. H. Secher, and H. Galbo, "Regulation of hepatic glucose production during exercise in humans: role of sympathoadrenergic activity," American Journal of Physiology-Endocrinology and Metabolism, vol. 265, no. 2, pp. E275-E283, 1993.

[59] M. Kjaer, K. Engered, H. Galbo et al., "Hepatic glucose production during exercise in liver-transplanted subjects," Scandinavian Journal of Gastroenterology, supplement 26, p. 46A, 1991.

[60] E. D. Berglund, R. S. Lee-Young, D. G. Lustig et al., "Hepatic energy state is regulated by glucagon receptor signaling in mice," Journal of Clinical Investigation, vol. 119, no. 8, pp. 2412-2422, 2009.

[61] J. M. Lavoie, "The contribution of afferent signals from the liver to metabolic regulation during exercise," Canadian Journal of Physiology and Pharmacology, vol. 80, no. 11, pp. 10351044, 2002.

[62] C. Longuet, E. M. Sinclair, A. Maida et al., "The glucagon receptor is required for the adaptive metabolic response to fasting," Cell Metabolism, vol. 8, no. 5, pp. 359-371, 2008.

[63] N. J. Christensen and H. Galbo, "Sympathetic nervous activity during exercise," Annual Review of Physiology, vol. 45, pp. 139$153,1983$.

[64] G. Van Dijk, B. Balkan, J. Lindfeldt et al., "Contribution of liver nerves, glucagon, and adrenaline to the glycaemic response to exercise in rats," Acta Physiologica Scandinavica, vol. 150, no. 3, pp. 305-313, 1994.

[65] R. G. McMurray, W. A. Forsythe, M. H. Mar, and C. J. Hardy, "Exercise intensity-related responses of $\beta$-endorphin and catecholamines," Medicine and Science in Sports and Exercise, vol. 19, no. 6, pp. 570-574, 1987.

[66] F. L. Tavares and M. C. L. Seelaender, "Hepatic denervation impairs the assembly and secretion of VLDL-TAG," Cell Biochemistry and Function, vol. 26, no. 5, pp. 557-565, 2008. 


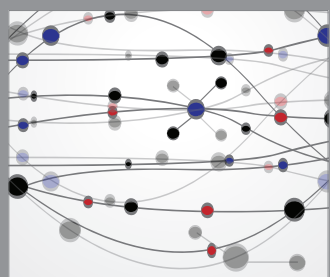

The Scientific World Journal
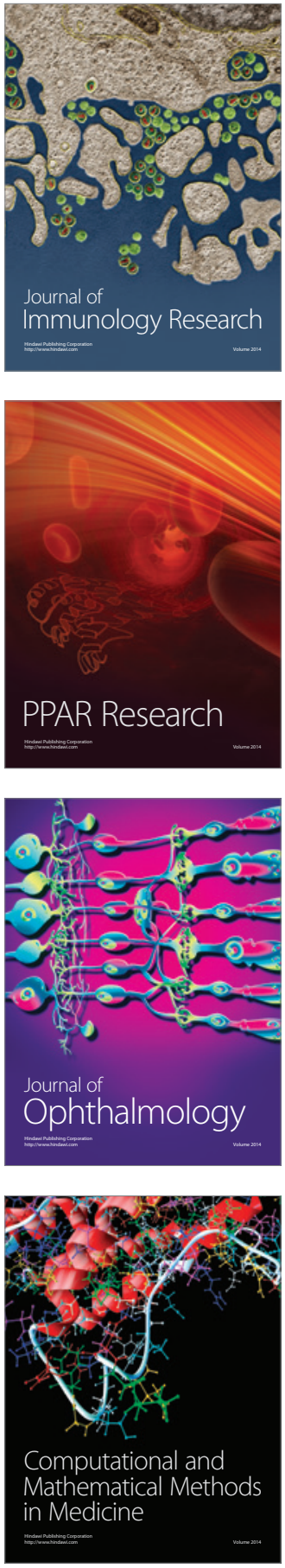

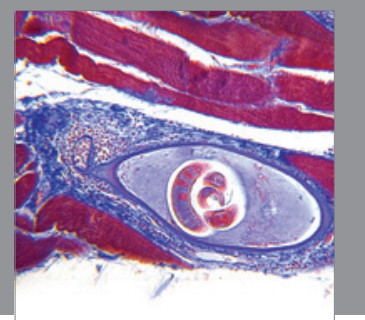

Gastroenterology

Research and Practice
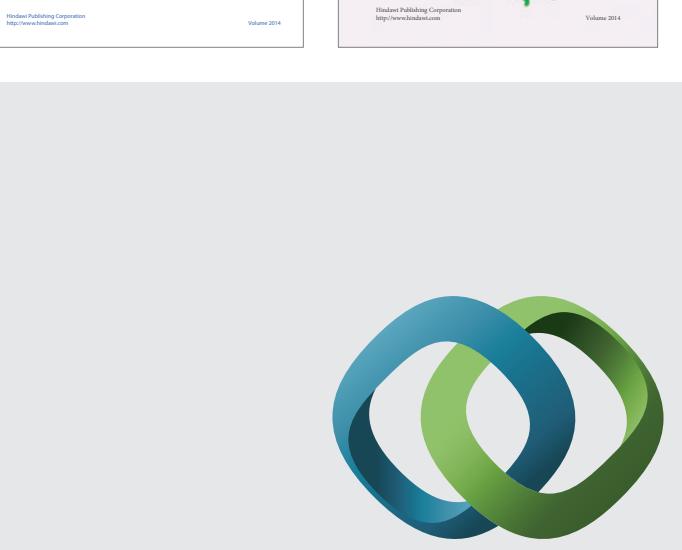

\section{Hindawi}

Submit your manuscripts at

http://www.hindawi.com
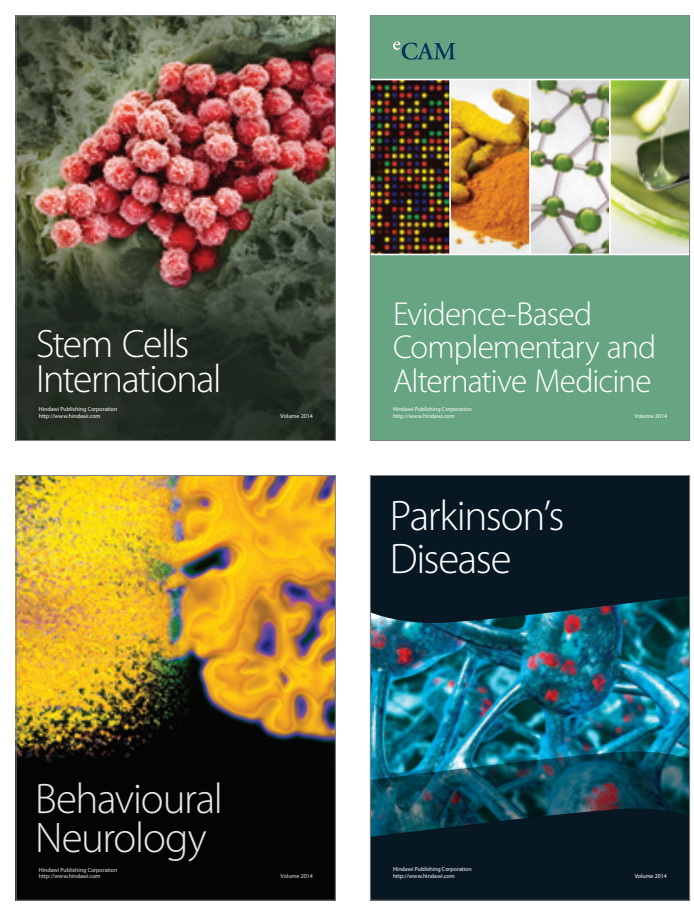

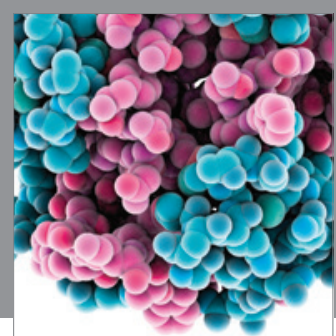

Journal of
Diabetes Research

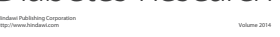

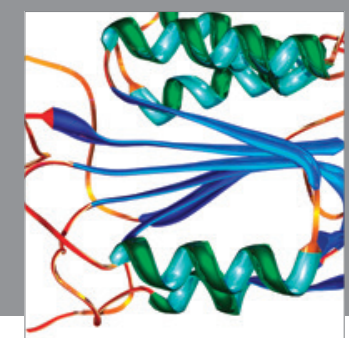

Disease Markers
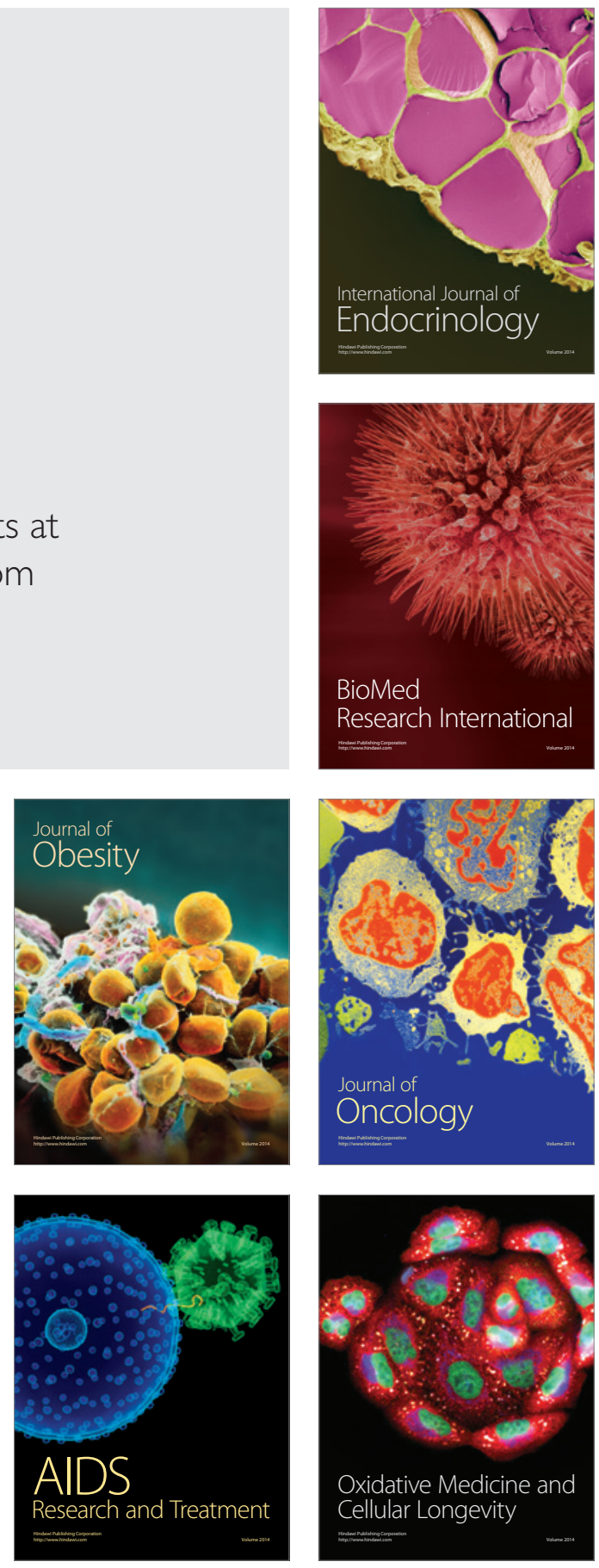